\title{
Thermodynamic analysis of high pressure methane adsorption in Longmaxi shale
}

Xu Tang*, Nino Ripepi ${ }^{*}{ }^{+}$, Nicholas P. Stadie $^{\ddagger}$, Lingjie, $\mathrm{Yu}^{\S, \pi}$

\begin{abstract}
Thermodynamic analyses of high pressure methane adsorption in shale are rarely reported because of the lack of a reliable approach for obtaining the true adsorption uptake from observed adsorption isotherms and the routinely used, oversimplified Clausius-Clapeyron (C-C) approximation. This work extends our previously proposed dual-site Langmuir adsorption model to calculate the isosteric heat of adsorption analytically from the observed adsorption isotherms for high pressure methane adsorption isotherms on Longmaxi shale from Sichuan, China (up to $27 \mathrm{MPa}$ and $355.15 \mathrm{~K}$ ). The calculated isosteric heat of adsorption considers both the real gas behavior of bulk methane and the adsorbed phase volume, which are neglected in the $\mathrm{C}-\mathrm{C}$ approximation. By this method, the temperature dependence as well as the uptake dependence of the isosteric heat can be readily investigated, where the former cannot be revealed using the $\mathrm{C}-\mathrm{C}$ approximation. The influence of the adsorbed phase and the gas behavior (real gas or ideal gas) on the isosteric heat of adsorption are also investigated, which shows that neglecting either the real gas behavior or the adsorbed phase volume always results in an overestimation of the isosteric heat of adsorption. In the Henry's law regime of low pressure and low adsorption uptake (and up to a surface occupancy of $<0.5$ ), the isosteric heat of adsorption of methane on Longmaxi shale is approximately constant at $15-17 \mathrm{~kJ} / \mathrm{mol}$, but then decreases significantly at higher pressures. This work therefore justifies the method to obtain the true isosteric heat of adsorption for high pressure methane in shale, which lays the foundation for future investigations of the thermodynamics and heat transfer characteristics of the interaction between high pressure methane and shale.
\end{abstract}

Key words: methane, shale gas, adsorption, Langmuir isotherm, isosteric heat of adsorption

Page 1 of 17 


\section{Introduction}

Shale gas has long been recognized as a promising alternative source of natural gas, and increasing demands for energy have led to a widespread international effort to estimate the extent of its resources and develop its production [1,2]. The gas found in shale formations is fundamentally different from conventional natural gas in that the formation itself is both the source and the reservoir. Within the porous formation, the total shale gas content consists of bulk gas (in larger pore spaces), dissolved gas (in the liquid brine), and adsorbed gas on the solid surface. This adsorbed component varies widely from resource to resource, accounting for $20 \%$ to $80 \%$ of the total shale gas content in five formations investigated in the United States $[3,4]$. Nevertheless, it is clear that the adsorbed quantity is a significant component that must be taken into account in accurate estimations of the total gas-in-place resource and the working life of a producing well. Methane adsorption in carbonaceous shale has been extensively studied over an intermediate range of temperature and pressure but high pressure $(>15$ MPa) studies have remained less common [5-10]. Furthermore, the thermodynamic characteristics of methane adsorbed on shale have rarely been considered, especially at high pressure. Shale formations at depths of $1500 \mathrm{~m}$ to $2500 \mathrm{~m}$ below the surface exist under conditions between $330-360 \mathrm{~K}$ and up to $38 \mathrm{MPa}$ (given a pressure coefficient of $15 \mathrm{MPa} / \mathrm{km}$ and geothermal gradient of $27.3{ }^{\circ} \mathrm{C} / \mathrm{km}$ as found in Longmaxi formations) [11], where common approximations as to the ideal nature of the bulk gas are no longer applicable and where the accurate prediction of the true adsorbed amount is not trivial. Understanding the thermodynamic properties of the adsorbed phase is important for evaluating the value of a deep shale resource, as in other adsorption systems such as gas separation and purification applications, adsorption chillers, and adsorptive energy storage [12-17].

Physical adsorption (or physisorption) at the gas-solid interface is the process of gas adsorbate accumulation on the surface of the solid adsorbent as a consequence of the weak van der Waals forces that exist between any two species [18]. The change in heat associated with physical adsorption is negative and significantly lower in magnitude than for chemical adsorption. Methane and shale can only interact via London dispersion forces (neither has a permanent dipole), the weakest type of van der Waals interactions, and the change in enthalpy is typically only $10-22 \mathrm{~kJ} / \mathrm{mol}[5]$. In this system, the quantity of adsorbed methane changes as a function of temperature and pressure so that the adsorbed phase and the bulk fluid phase are at the same chemical potential. The specific quantity is not only influenced by material properties of the shale (e.g., organic components, minerals, and surface structure) but also by the composition of the gas adsorbate (e.g., content of moisture) [5-10]. The isosteric heat of adsorption can also vary as a function of the amount of adsorbate and the system conditions [19-21]. It therefore serves as an important descriptor of the physisorption system, and is directly related to the strength of the interaction between gas adsorbate and solid adsorbent $[22,23]$. The isosteric heat of adsorption typically decreases as adsorption uptake increases because of binding site (and therefore binding energy) heterogeneity [20, 24, 25].

Thermodynamic analysis of the properties of the adsorbed phase is possible by measuring the properties of the bulk gas that is in equilibrium with it. However, the Gibbs excess adsorption (measured) quantity is an underestimation of the absolute amount adsorbed $[19,26]$. At low pressure, the experimental adsorption isotherm well approximates the absolute isotherm; however, at high pressure, the observed adsorbed content first reaches a maximum and then decreases with increasing pressure 
which is not consistent with the physical nature of adsorption [26]. Thus, it is necessary to calculate the isosteric heat of adsorption along absolute isosteres and an effective method for their determination is needed. Furthermore, there are several issues associated with the calculation of the isosteric heat of adsorption directly from observed adsorption isotherms (where the observed adsorption quantity is also called the Gibbs excess adsorption uptake) [19, 26-28]. First, a direct, uniform approach for obtaining the absolute quantity of adsorption from measured adsorption isotherms has not been developed, and the correct modeling of the physical parameters of the adsorbed phase such as its density are complex issues that remain actively discussed [27-33]. Second, a consideration of the deviation of real gas behavior from the ideal gas law is necessary when calculating the isosteric heat of adsorption, especially under high pressure and low temperature conditions. Methane deviates significantly from the ideal gas law at pressures above $6 \mathrm{MPa}$ at room temperature as shown in Figure 1. For methane adsorption in shale, the $\mathrm{C}-\mathrm{C}$ approximation is routinely used to calculate the isosteric heat of adsorption. However, since the $\mathrm{C}-\mathrm{C}$ approximation ignores the adsorbed phase effect and uses the ideal gas law, the calculated results may not reveal the true thermodynamics behavior for methane in shales. In order to reasonably analyze the thermodynamic characteristics of a gas-solid system such as methane in shale, the above issues must be addressed [19, 27, 34, 35].

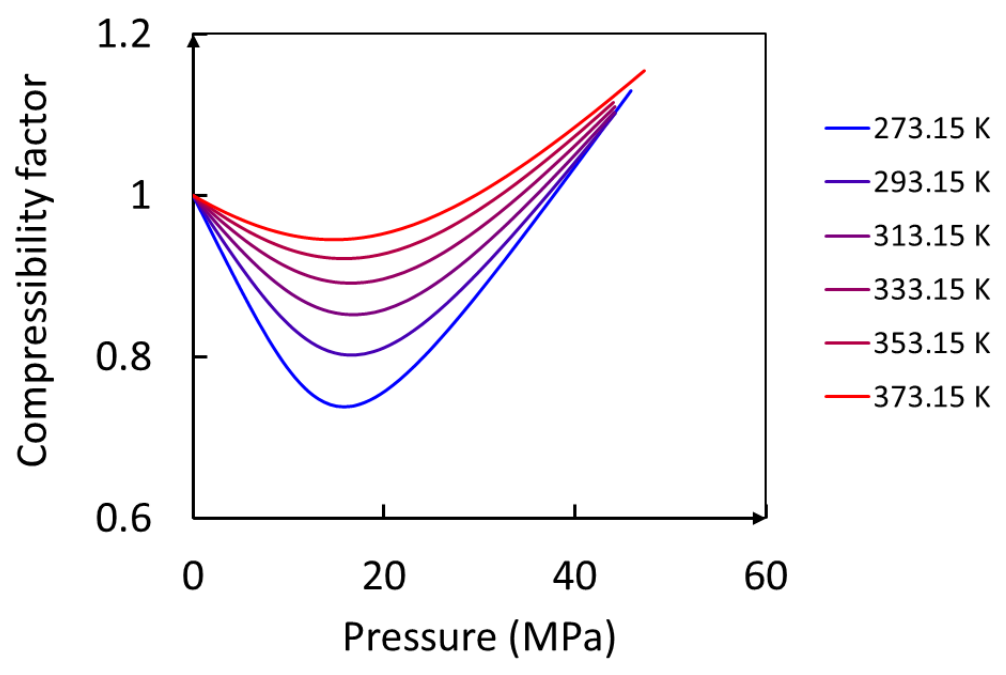

Figure 1. Compressibility factor of methane between 0-50 MPa and 273-373 K (as obtained from the NIST REFPROP database, version 8.0)

In previous work, we applied a dual-site Langmuir model to obtain absolute adsorption isotherms from observed Gibbs excess adsorption equilibria utilizing the assumption that the density of the adsorbed phase is an unknown constant [36]. The proposed model gives a reasonable explanation for all observed phenomena in high pressure methane adsorption in shales, which have not been reasonably addressed using the conventional Langmuir model, the potential theory based model, or their revised forms [36]. Considering the justification of its use, the dual-site Langmuir model is therefore extended in this work to calculate the isosteric heat of adsorption analytically for high pressure methane on shale. This method considers both the real gas behavior of the bulk methane and the volume of the adsorbed phase, both of which are neglected in the classic C-C approach. The influence of the adsorbed phase volume and the nature of the gas behavior (real or ideal) on the isosteric heat of adsorption are also investigated. Calculations in the Henry's law region (corresponding to the limit of low pressure) were 
also performed based on the absolute methane adsorption isotherms to validate the above methodology. Rouquerol's approach [37] is applied in this case to avoid any potential for subjective judgements in determining the properties of the adsorbed phase in the Henry's law pressure range arising from the use of high pressure gas adsorption isotherm data.

\section{Thermodynamic analysis}

\subsection{Absolute adsorption quantity calculation}

Based on the assumption that the volume of the adsorbed layer monotonically increases with increased pressure and the density remains constant, the dual-site Langmuir model has been successfully used to simulate the Gibbs excess adsorption quantity $\left(n_{e}(P, T)\right)$ in shale, as shown in equation (1),

$$
n_{e}(P, T)=\left(n_{\max }-V_{\max } \cdot \rho(P, T)\right) \cdot\left[(1-\alpha)\left(\frac{K_{1}(T) P}{1+K_{1}(T) P}\right)+\alpha\left(\frac{K_{2}(T) P}{1+K_{2}(T) P}\right)\right]
$$

Then, both the absolute adsorption quantity $\left(n_{a}(P, T)\right.$, equation (2)) and surface coverage $(\theta$, equation (3))as a function of temperature and pressure can be obtained via global curve fitting of the entire set of Gibbs excess uptake isotherms,

$$
n_{a}(P, T)=n_{\max } \cdot\left[(1-\alpha)\left(\frac{K_{1}(T) P}{1+K_{1}(T)_{1} P}\right)+\alpha\left(\frac{K_{2}(T) P}{1+K_{2}(T) P}\right)\right]
$$

$\theta=\frac{n_{a}(P, T)}{n_{\max }}=\left[(1-\alpha)\left(\frac{K_{1}(T) P}{1+K_{1}(T) P}\right)+\alpha\left(\frac{K_{2}(T) P}{1+K_{2}(T) P}\right)\right]$

The density of the adsorbed density, $\rho_{a d}$, can also be obtained based on fitting parameters of equation (1),

$$
\rho_{a}=\frac{n_{\max }}{V_{\max }}
$$

The volume of the adsorbed phase, which is the ratio between absolute adsorption mass (quantity) and density, can be obtained as shown in equation (5),

$$
v_{a}=\frac{n_{a}}{\rho_{a d}}=V_{\max } \cdot\left[(1-\alpha)\left(\frac{K_{1}(T) P}{1+K_{1}(T) P}\right)+\alpha\left(\frac{K_{2}(T) P}{1+K_{2}(T) P}\right)\right]
$$

Equations (2) and (5) lay the foundation for obtaining the true behavior of the isoteric heat of adsorption for high pressure gas adsorption.

\subsection{Isosteric heat of adsorption}

The change in enthalpy of the system due to adsorption at a specific state of surface occupancy is referred to as the isosteric heat of adsorption $\left(\Delta H_{a d s}\right)$. It can be determined via the Clapeyron relationship which is relevant to the equilibrium between two phases (in this case the adsorbed phase, a, and the gas phase, $\mathrm{g}$ ) in a closed system:

$\Delta H_{a d s}=\left(\frac{d P}{d T}\right)_{n_{a}} \cdot T \cdot \Delta v=\left(\frac{d P}{d T}\right)_{n_{a}} \cdot T \cdot\left(v_{a}-v_{g}\right)$

The derivative of pressure with temperature along an isostere (constant value of adsorption uptake), $\left(\frac{d P}{d T}\right)_{n a}$, can be expanded in various ways for further investigation. Since the pressure in a closed 
system is a function of temperature and quantity adsorbed, a general expansion may be made such that 145 [40],

$$
\left(\frac{d P}{d T}\right)_{n_{a}}=\left(\frac{\partial P}{\partial n_{a}}\right)_{T} \frac{d n_{a}}{d T}+\left(\frac{\partial P}{\partial T}\right)_{n_{a}}=\left(\frac{\partial P}{\partial n_{a}}\right)_{T} \frac{d n_{a}}{d T}+P\left(\frac{\partial(\ln P)}{\partial T}\right)_{n_{a}}
$$

147 If the bulk fluid is approximated as an ideal gas, $v_{g}=R T / P$, equation (8) can be obtained by inserting 148 both equation (7) and $v_{g}$ into equation (6),

$$
-\Delta H_{a d s\left(n_{a}\right)}=R T^{2}\left[\left(\frac{\partial(\ln P)}{\partial T}\right)_{n_{a}}\right]+\frac{R T^{2}}{P} \cdot\left(\frac{\partial P}{\partial n_{a}}\right)_{T} \frac{d n_{a}}{d T}-\left[\left(\frac{\partial P}{\partial n_{a}}\right)_{T} \frac{d n_{a}}{d T}+P\left(\frac{\partial(\ln P)}{\partial T}\right)_{n_{a}}\right] \cdot T \cdot v_{a}
$$

150 In right hand side (RHS) of equation (8), the second term, $\frac{R T^{2}}{P} \cdot\left(\frac{\partial P}{\partial n_{a}}\right)_{T} \frac{d n_{a}}{d T}$, includes the behavior of 151 the adsorbed phase mass, and the third term, $\left[\left(\frac{\partial P}{\partial n_{a}}\right)_{T} \frac{d n_{a}}{d T}+P\left(\frac{\partial(\ln P)}{\partial T}\right)_{n_{a}}\right] \cdot T \cdot v_{a}$, considers the volume effect of the adsorbed phase. If the volume of the adsorbed layer is taken to be negligible and the influence of the adsorbed mass is ignored, the conventional Clausius-Clapeyron (C-C) relationship is obtained:

$$
\Delta H_{a d s}=\Delta H_{a d s, c-c}=R T^{2}\left[\left(\frac{\partial(\ln P)}{\partial T}\right)_{n_{a}}\right]
$$

Optionally, if the relationship between the amount adsorbed and the process conditions (pressure and temperature) is known, the derivative can be directly determined. If that relationship is taken to have the form of a Langmuir equation, then the derivative can be expanded into three simpler terms:

$$
\left(\frac{d P}{d T}\right)_{n_{a}}=\left(\frac{\partial P}{\partial \theta}\right)_{n_{a}} \cdot\left(\frac{\partial \theta}{\partial K}\right)_{n_{a}} \cdot\left(\frac{\partial K}{\partial T}\right)_{n_{a}}
$$

By combining equation (6) with equation (10), the isosteric heat of adsorption is then directly obtained. There are numerous ways to handle the difference between the molar volume of the gas and adsorbate as required to solve equation (6). For example, by applying the ideal gas law ( $P v=R T$ ), one form of the isosteric heat of adsorption can be obtained simply as,

$$
-\Delta H_{a d s\left(n_{a}\right), I G L}=\left(\frac{\partial P}{\partial \theta}\right)_{n_{a}} \cdot\left(\frac{\partial \theta}{\partial K}\right)_{n_{a}} \cdot\left(\frac{\partial K}{\partial T}\right)_{n_{a}} \cdot T \cdot\left(\frac{R T}{P}-v_{a}\right)
$$

Ignoring the volume of the adsorbed phase (in other words, assuming $v_{a} \ll<v_{g}$ ), another form of the isosteric heat of adsorption can be obtained,

$167-\Delta H_{a d s\left(n_{a}\right), I G L-0 V}=\left(\frac{\partial P}{\partial \theta}\right)_{n_{a}} \cdot\left(\frac{\partial \theta}{\partial K}\right)_{n_{a}} \cdot\left(\frac{\partial K}{\partial T}\right)_{n_{a}} \cdot T \cdot\left(\frac{R T}{P}\right)$ 
If equation (6) and equation (10) are combined and the true gas density (which can be obtained using the NIST REFPROP database, version 8.0) is applied instead of the ideal gas law density, the isosteric heat of adsorption is obtained as,

$-\Delta H_{a d s\left(n_{a}\right), R G L}=\left(\frac{\partial P}{\partial \theta}\right)_{n_{a}} \cdot\left(\frac{\partial \theta}{\partial K}\right)_{n_{a}} \cdot\left(\frac{\partial K}{\partial T}\right)_{n_{a}} \cdot T \cdot\left(\rho_{g}^{-1}-v_{a}\right)$

Ignoring the volume of the adsorbed phase in equation (13), an additional form of the isosteric heat of adsorption can be obtained,

$$
-\Delta H_{a d s\left(n_{a}\right) R G L-0 V}=\left(\frac{\partial P}{\partial \theta}\right)_{n_{a}} \cdot\left(\frac{\partial \theta}{\partial K}\right)_{n_{a}} \cdot\left(\frac{\partial K}{\partial T}\right)_{n_{a}} \cdot T \cdot\left(\rho_{g}^{-1}\right)
$$

Equations (11)-(14) are much easier to solve using an analytical approach than equation (8). The analytical form of $\left(\frac{\partial P}{\partial \theta}\right)_{n_{a}} \cdot\left(\frac{\partial \theta}{\partial K}\right)_{n_{a}} \cdot\left(\frac{\partial K}{\partial T}\right)_{n_{a}}$ in the case of the dual-site Langmuir equation (equation (2)) is:

$$
\left(\frac{\partial P}{\partial \theta}\right)_{n_{a}} \cdot\left(\frac{\partial \theta}{\partial K}\right)_{n_{a}} \cdot\left(\frac{\partial K}{\partial T}\right)_{n_{a}}=\frac{\frac{(1-\alpha) P}{\left(1+K_{1}(T) P\right)^{2}} \cdot \frac{-E_{1} K_{1}(T)}{R T^{2}}+\frac{\alpha P}{\left(1+K_{2}(T) P\right)^{2}} \cdot \frac{-E_{2} K_{2}(T)}{R T^{2}}}{\frac{(1-\alpha) K_{1}(T)}{\left(1+K_{1}(T) P\right)^{2}}+\frac{\alpha K_{2}(T)}{\left(1+K_{2}(T) P\right)^{2}}}
$$

The merits of the second approach (equation (10) over equation (7)) are twofold. Firstly, both the true gas behavior and the ideal gas law can easily be implemented as shown in equations (11) and (13), to determine the effect of assuming gas phase ideality in the result. Secondly, the volume of the adsorbed layer can also be taken into consideration, an especially important feature to account for outside of the low-pressure (Henry's law) limit. On the contrary, the conventional C-C equation inherently adopts the ideal gas law and does not consider the density of the adsorbed layer to be significant compared to the bulk gas.

\subsection{The Henry's law limit}

An approximate approach is provided here to extrapolate the isosteric heat of adsorption to low pressures (the Henry's law region) from the as-collected high pressure adsorption isotherms. In this way, an unbiased isosteric heat of adsorption can be calculated without the dependence on any model or specific methodology, for comparison to the method described above.

In the limit of low pressure, gas adsorption behavior follows Henry's law,

$$
n_{a}=K_{H} P
$$

where $\mathrm{P}$ is the pressure of the bulk gas, $n_{a}$ is the absolute adsorption content, and $\mathrm{K}_{\mathrm{H}}$ is the Henry's law constant. Together with the van't Hoff equation (which relies on the ideal gas law, also applicable in the Henry's law regime), the relationship between $\mathrm{K}_{H}$ and the thermodynamic quantities of adsorption is expressed as, 
$\ln K_{H}=-\frac{\Delta H_{H}}{R T}+\frac{\Delta S_{H}}{R}$

The isosteric heat of adsorption in the Henry's law region can be obtained from the linear relationship between $\ln \left(\mathrm{K}_{\mathrm{H}}\right)$ and the reciprocal of T. The key step at this point is to obtain the Henry's law constant using a reasonable pressure range wherein the linear relationship between absolute adsorption content and pressure is valid.

In order to calculate Henry's law constants, the relationship between adsorption uptake and pressure in the low-pressure region can be expressed by a virial expansion,

$\ln \left(n_{a} / P\right)=A_{0}+A_{1} n_{a}+A_{2} n_{a}^{2}+\cdots \cdots$

where $n_{a}$ is the absolute content of adsorption at bulk gas pressure $P$, and the first virial coefficient $A_{0}$ is related to the Henry's law constant, $K_{H}$, as $K_{H}=\exp \left(A_{0}\right)$. When $n_{a}$ is small, the higher-order terms can be neglected, and equation (18) can be written as,

$\ln \left(P / n_{a}\right)=-A_{0}-A_{1} n_{a}$

From equation (19), $A_{0}$ can then be obtained by fitting the linear region of $\ln \left(P / n_{a}\right)$ as a function of $n_{a}$, where $n_{a}$ is approximated by measured $n_{e}$ isotherms. Rouquerol's recommended approach [37] is applied herein to avoid any subjective judgements in determining the Henry's law pressure range:

a. the application of equation (19) should be limited to the pressure range where the term $n_{a}(1-$ $\left.P / P_{\max }\right)$ continuously increases with $P / P_{\max }\left(P_{\max }\right.$ is the maximum pressure investigated).

b. an apparent linear relationship must be obtained, i.e., the correlation coefficient $\left(R^{2}\right)$ should be above 0.95 .

Once Henry's law constant values are obtained, the isosteric heat of adsorption in the Henry's law region can be obtained from the linear relationship between $\ln \left(\mathrm{K}_{H}\right)$ and the reciprocal of temperature as shown in equation (17).

\section{Experimental data and analysis}

Four high-pressure adsorption isotherms of methane on Longmaxi shale (China) were measured using the gravimetric method: at $303.15 \mathrm{~K}, 318.15 \mathrm{~K}, 333.15 \mathrm{~K}$, and $355.15 \mathrm{~K}$ (Figure 2) [36]. All four isotherms were then fitted simultaneously to the dual-site Langmuir model (equation 1 ) by a least-squares residual minimization algorithm based on the Differential Evolution method as implemented by Mathematica software (version 9.0.1). Each data point was given the same weight and none were discarded. Minimization was performed in excess of 100 unique times by changing the random seed in order to ensure that a global minimum was achieved. The seven independent fitting parameters were varied to achieve the global minimum of the residual-squares value within the following limits: $0<\mathrm{n}_{\max }<100$ $\mathrm{mmol} / \mathrm{g}, 0<\mathrm{V}_{\max }<10 \mathrm{~mL} / \mathrm{g}, 0<\alpha<1,0<\mathrm{E}_{1}<100 \mathrm{~kJ} / \mathrm{mol}, 0<\mathrm{E}_{2}<100 \mathrm{~kJ} / \mathrm{mol}, \mathrm{A}_{1}>0$, and $\mathrm{A}_{2}>0$. Once the best-fit parameters were determined, absolute and excess adsorption uptake could be expressed at arbitrary temperatures and pressures by use of equations (2) and (4). As shown in Figure 2, the dual-site Langmuir adsorption model (equation 1) gives a good global fit to the observed data, with a total residual sum of squares of 0.0147 ( 0.000263 per point). The corresponding best-fit parameters are: $\mathrm{n}_{\max }$ $=0.1715 \mathrm{mmol} / \mathrm{g}, \mathrm{V}_{\max }=0.0097 \mathrm{~mL} / \mathrm{g}, \alpha=0.2640, \mathrm{E}_{1}=16.706 \mathrm{~kJ} / \mathrm{mol}, \mathrm{A}_{1}=0.00021 / \mathrm{MPa}, \mathrm{E}_{2}=15.592$ 
$\mathrm{kJ} / \mathrm{mol}$, and $\mathrm{A}_{2}=0.00321 / \mathrm{MPa}$. Detailed experimental methods and material properties of the shale are described in our previous work [36].

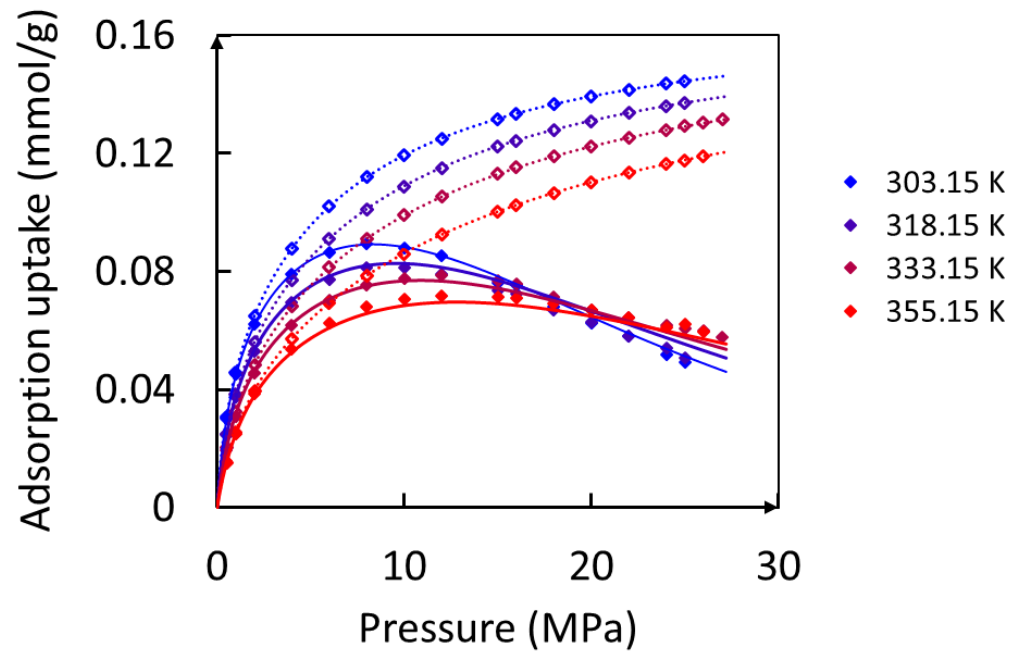

Figure 2. Equilibrium adsorption uptake of methane on Longmaxi shale between 303-355 $\mathrm{K}$ and 0.5-25 MPa: solid symbols are measured Gibbs excess uptake, solid lines are modeled Gibbs excess uptake (equation (1)), and open symbols and dashed lines are modeled absolute uptake (equation (2)). The data are reproduced from a previous study [36].

The well-known phenomenon that the observed Gibbs excess adsorption uptake increases with increasing pressure up to a maximum value and then decreases, as well as the corresponding crossover of isotherms, can be seen in Figure 2. The first is attributed to the increasing volume of the adsorbed phase with increasing pressure, leading to a maximum in the Gibbs excess adsorption at each temperature [36]. The crossover can be simply attributed to the PVT behavior of methane as a function of pressure, which has not been reasonably addressed using other commonly used adsorption models in literature. Furthermore, the temperature dependence of the adsorption uptake is built into the model in this work [36], where previously only empirical relationships or no relationship at all was addressed, making this globally fitted model more descriptive of temperature-related phenomena. As is characteristic of the physical nature of adsorption, the absolute adsorption quantity increases monotonically up to $27 \mathrm{MPa}$ at all temperatures. The temperature dependence of the absolute adsorption uptake is also clear: the higher the temperature the lower the absolute adsorption uptake. These features ensure that an accurate thermodynamic analysis can be achieved using the absolute adsorption equilibria calculated in this work.

\section{Thermodynamic analysis and discussion}

In the thermodynamic analysis of methane adsorption on shale performed in this work, the robustness of the isosteric heat of adsorption is first confirmed. Then, the various quantities describing the isosteric heat of adsorption (equations (11)-(14)) are compared to understand how the real gas behavior and the adsorbed phase volume influence the isosteric heat of adsorption. The temperature influence on the isosteric heat of adsorption is also compared. Finally, the isosteric heat of adsorption within the Henry's law pressure region is calculated to validate the above methodology using the high pressure methane absolute adsorption isotherms. 


\subsection{Robustness of the isosteric heat of adsorption calculation}

264

265

266

267

268

269

270

271

272

273

274

275

276

277

278

279

280

281

The isosteric heat of adsorption is best calculated by including all measured adsorption data in the fitting routine, obtaining the best-fit parameters, and then directly solving equation (13) to obtain $-\Delta H_{\text {ads, }}$ which not only considers the real gas behavior but also takes the volume of the adsorbed phase into consideration. The isosteric heat of adsorption of methane on shale, as a function of absolute quantity of methane adsorbed, is shown as solid isothermal lines in Figure 3. The isosteric heat varies from 16.5 $\mathrm{kJ} / \mathrm{mol}$ at low pressure and high temperature $(355 \mathrm{~K})$, down to $<5 \mathrm{~kJ} / \mathrm{mol}$ at high pressures, indicating a heterogeneous distribution of adsorption sites in the porous shale structure.

To demonstrate the robustness of the analytical calculation of the isosteric heat of adsorption by our method, the results obtained using different processing approaches are compared in Figure 3: (1) using all measured data (solid lines), (2) using only the data between 0-15 MPa (small dashes), and (3) using only the data between $303.15-333.15 \mathrm{~K}$ as fitting data to obtain a best fit (large dashes). Method (1) represents the best approach as described previously, and method (2) and (3) demonstrate the effects of collecting less experimental data (e.g., at $<15 \mathrm{MPa}$ as in a majority of previous investigations). As shown in Figure 3, the resulting isosteric heats are approximately the same except in the low pressure region. While this may seem counterintuitive, it is important to note that subtle changes in the best-fit parameters lead to large changes in the $\mathrm{dP} / \mathrm{dT}$ term in equation (10) and (15), and the best-fit parameters can only be achieved by using a large range of measured data (typically requiring numerous isotherms and data extending well beyond the Gibbs excess maximum).

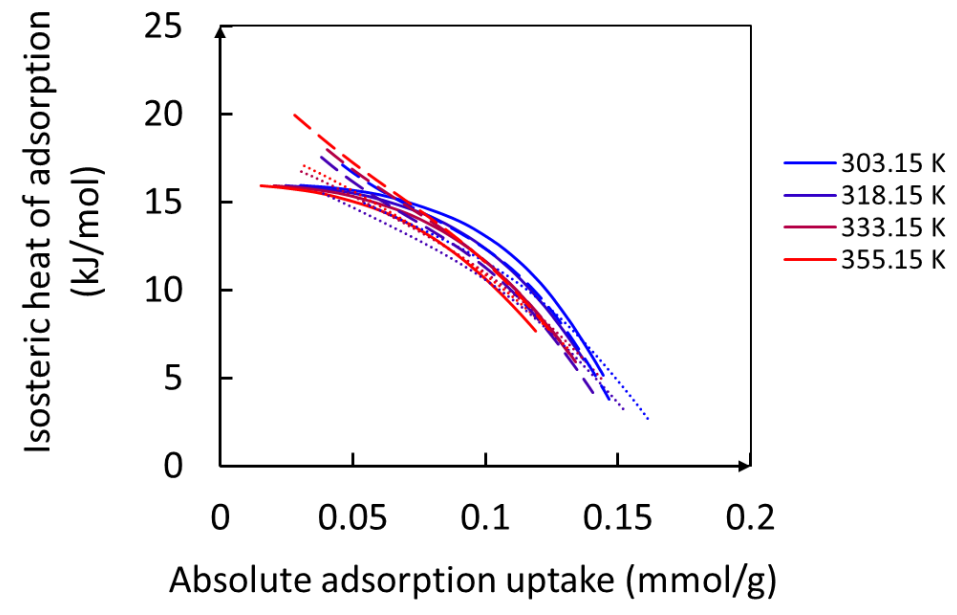

Figure 3. Isosteric heat of adsorption of methane on shale between 303-355 $\mathrm{K}$ (blue to red) as a function of absolute adsorption uptake (solid lines). For comparison, the isosteric heat calculated by including experimental data from restricted ranges of pressure and temperature is also shown (as small and large dashes, respectively).

\subsection{Effect of real gas behavior and adsorbed phase volume}

The second step is to investigate the effects of real gas behavior and the volume of the adsorbed phase on the isosteric heat of adsorption beyond the Henry's law region. A summary of the assumptions included within each isosteric heat of adsorption investigated herein is shown in Table 1 and a detailed discussion of the comparison with Henry's law analysis is given in Section 4.4. 
Table 1. Definition of various isosteric heats of adsorption

\begin{tabular}{|l|c|c|}
\hline \multicolumn{1}{|c|}{ Isosteric heat of adsorption } & Gas behavior & Adsorbed phase volume \\
\hline Heat of adsorption within the Henry's law region & Ideal gas & No \\
\hline$\Delta H_{a d s, c-c}:$ Equation (9) & Ideal gas & No \\
\hline$\Delta H_{a d s\left(n_{a}\right), I G L}:$ Equation (11) & Ideal gas & Yes \\
\hline$\Delta H_{a d s\left(n_{a}\right), I G L-0 V}:$ Equation (12) & Ideal gas & No \\
\hline$\Delta H_{a d s\left(n_{a}\right), R G L}:$ Equation (13) & Real gas & Yes \\
\hline$\Delta H_{a d s\left(n_{a}\right) R G L-0 V}:$ Equation (14) & Real gas & No \\
\hline
\end{tabular}

294 A comparison of the isosteric heats of adsorption calculated according to Table 1 is shown in Figure 4. 295 The different isosteric heats of adsorption follow a similar behavior irrespective of temperature and the 296 isosteric heat of adsorption at $303.15 \mathrm{~K}$ is taken as an example to interpret the influence of real gas 297 behavior and adsorbed phase volume. The C-C approximation employs the ideal gas law and does not 298 consider the adsorbed phase volume. Both assumptions become less valid with increasing adsorption 299 content and cause a significant overestimation of the isosteric heat of adsorption. Regardless of the gas 300 law employed, the adsorbed phase volume significantly affects the behavior of the calculated isosteric 301 heat of adsorption, especially under high pressure conditions: without considering $v_{a}$, the isosteric heat 302 of adsorption is always overestimated. For cases considering the finite volume of the adsorbed phase, 303 the difference between the real gas and ideal gas density also affects the isosteric heat of adsorption 304 significantly: the ideal gas law always corresponds to a higher isosteric heat. Comparing these effects at different temperatures, it can be found that as temperature increases, the influence of both the 306 equation of state of the gas and the volume of the adsorbed phase decreases.

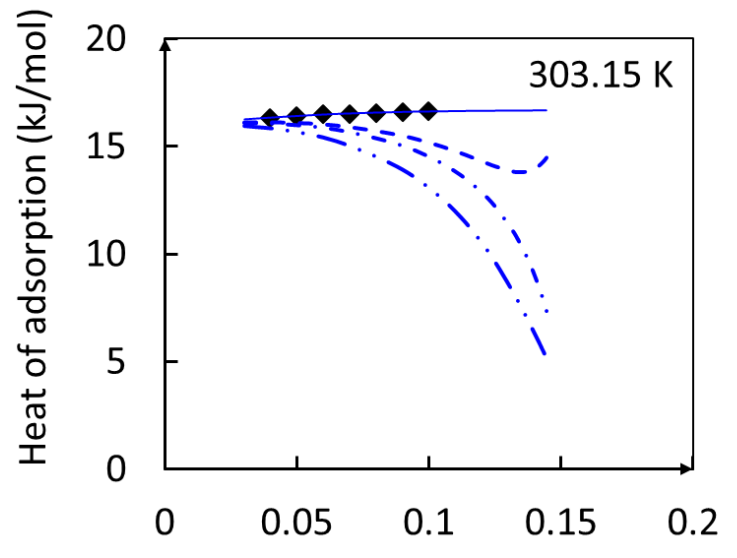

Absolute adsorption uptake $(\mathrm{mmol} / \mathrm{g})$

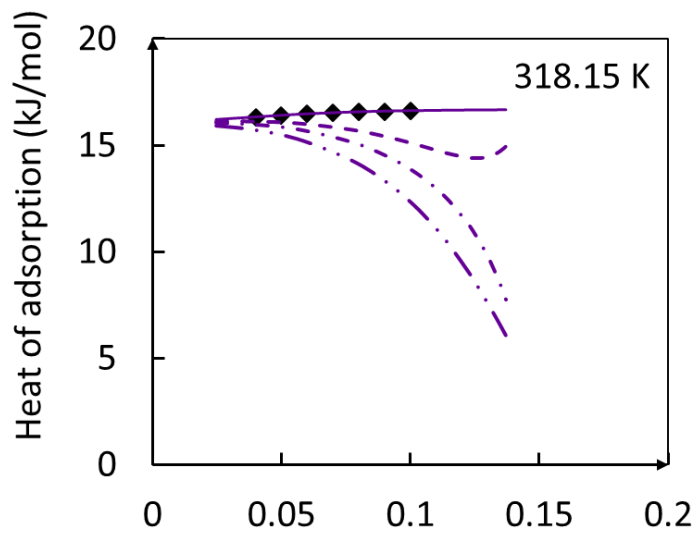

Absolute adsorption uptake ( $\mathrm{mmol} / \mathrm{g})$ 


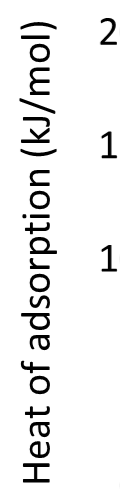

0
$333.15 \mathrm{~K}$

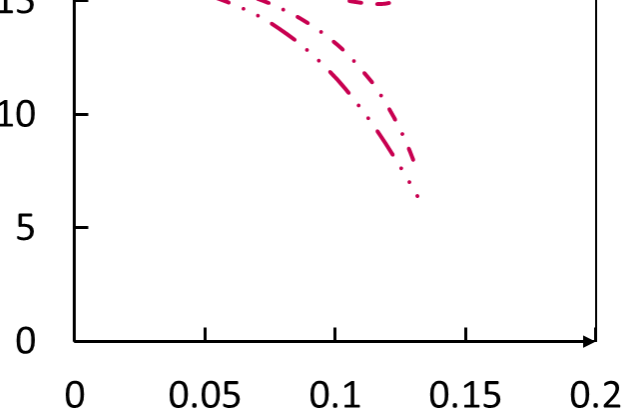

Absolute adsorption uptake ( $\mathrm{mmol} / \mathrm{g}$ )

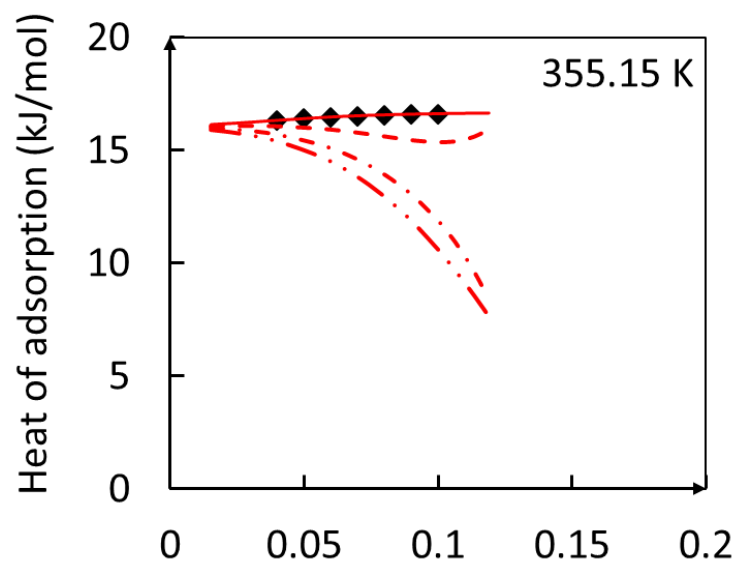

Absolute adsorption uptake $(\mathrm{mmol} / \mathrm{g})$

Figure 4. Isosteric heat of adsorption of methane on shale as calculated using four different methods:

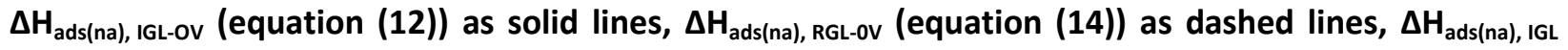
(equation (11)) as single dotted lines, and $\Delta H_{\text {ads(na), } R G L}$ (equation (13)) as double dotted lines. The isosteric heat of adsorption calculated in the C-C approximation (equation (9)) is also shown as filled black symbols.

\subsection{Effect of temperature}

Isosteric heats of adsorption calculated in different ways (according to equations (9) and (11)-(14)) are shown at all temperatures investigated in Figure 5. In all cases, temperature generally has a negative effect on the isosteric heat of adsorption for both real gas and ideal gas cases: the higher the temperature, the lower the isosteric heat of adsorption. Using the real gas equation of state, if the adsorbed phase volume is ignored, isosteric heats of adsorption first decrease and then increase and the temperature-dependence reverses at high pressure. In the ideal gas assumption (Figure 5a), if the adsorbed phase volume is ignored, the isosteric heat of adsorption becomes the C-C approximation and the temperature-dependence disappears altogether. This is also shown in Figure $5 \mathrm{a}$ in that the

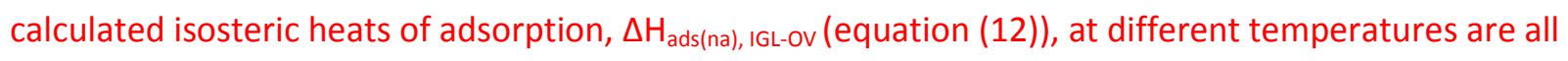
equal to the $\mathrm{C}-\mathrm{C}$ approximation. As shown in both Figures $5 \mathrm{a}$ and $5 \mathrm{~b}$, the adsorbed phase has a stronger influence on the calculated isosteric heat of adsorption compared to temperature. Ignoring the volume effect of the adsorbed phase results in an overestimation of the isosteric heat of adsorption, especially under high pressure conditions. Figure 5 also shows that in the low pressure region (i.e., low adsorption uptake), the isosteric heats of adsorption merge at a constant value. However, because limited data were measured in this region, extrapolation to the limiting value is difficult. This problem can be solved using the approach discussed in Section 4.4. 


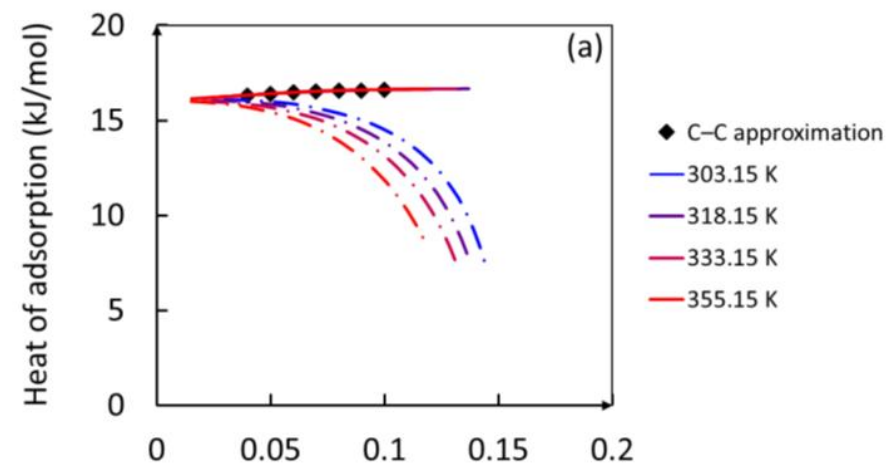

Absolute adsorption uptake ( $\mathrm{mmol} / \mathrm{g}$ )

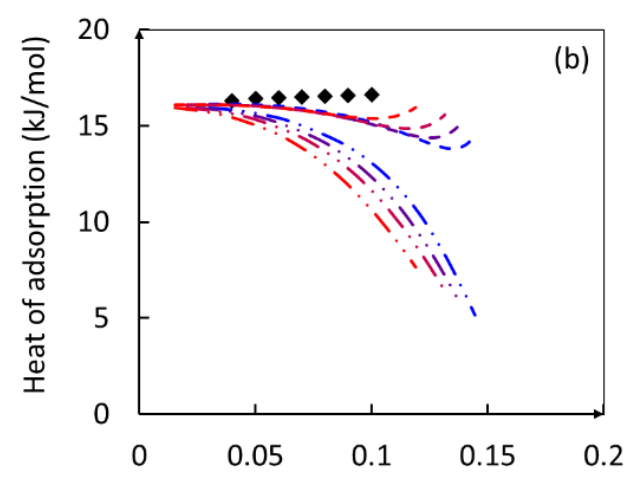

Absolute adsorption uptake ( $\mathrm{mmol} / \mathrm{g})$

Figure 5. Comparison of different methods of calculation of the isosteric heat of adsorption of

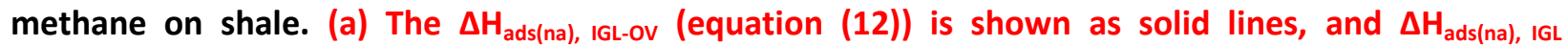

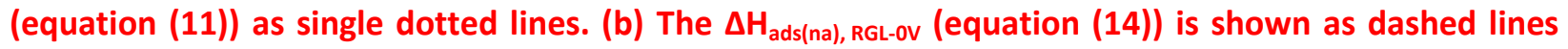

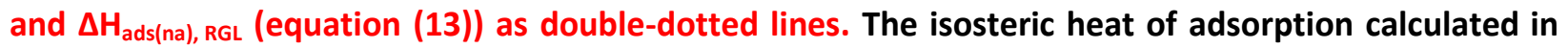
the C-C approximation (equation (9)) is also shown as filled black symbols.

\subsection{Determination of the Henry's law limit}

As shown in Section 2.3, the first step to calculate isosteric heat of adsorption in the Henry's law region is to determine the Henry's law pressure range. Figure (6a) shows how Rouquerol's approach is applied. Once the Henry's law pressure ranges are determined, equation (19) is used to calculate the $A_{0}$ value. This is shown in Figure (6b), and the $A_{0}$ value can then be obtained by fitting the linear region of $\ln \left(P / n_{a}\right)$ as a function of $n_{a}$. When $A_{0}$ is obtained, the Henry's law constant, $K_{H}$, can be obtained as, $K_{H}=\exp \left(A_{0}\right)$. Then, the mean isosteric heat of adsorption over the entire temperature range, calculated according to equation (17), is $16.5 \mathrm{~kJ} / \mathrm{mole}$ (see Figure 7). This is consistent with the value determined by both the analytical and conventional approaches as described above (Figures 4-5).
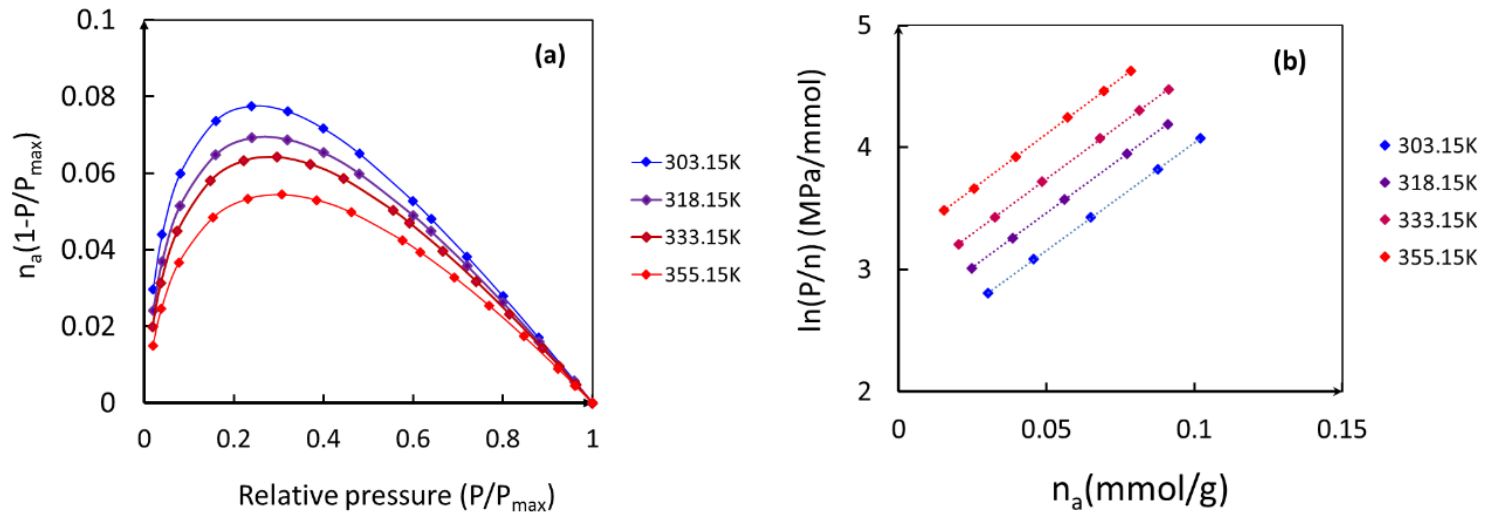

Figure 6. Equilibrium adsorption uptake of methane on shale $\left(n_{a}\right)$ between 303-355 K and 0.5-25 MPa, as measured (solid symbols) and as fitted by a virial-type equation (solid lines, equation (19)). (left) Adsorption uptake is shown as a product of $n_{a}$ and $1-P / P_{\max }$, as a function of $P / P_{\max }$ (right) Adsorption uptake is shown in the linear region for $\ln \left(P / n_{a}\right)$ as a function of $n_{a}$. 


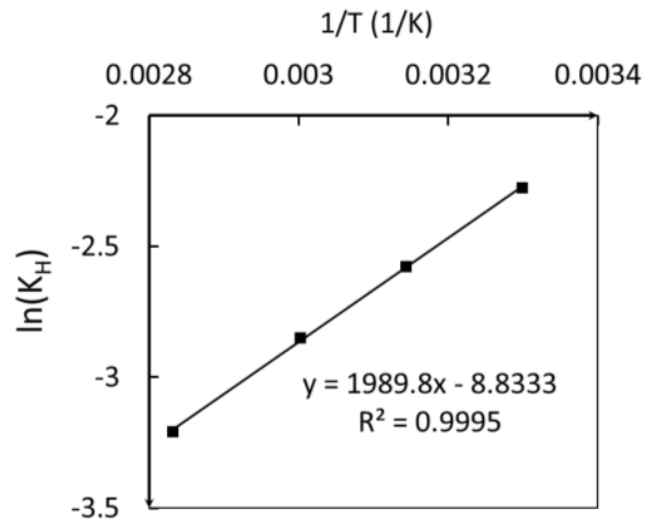

Figure 7. Mean isosteric heat of adsorption calculated by equation (17)

\section{Discussion}

Understanding the isosteric heat of adsorption is useful in accurate estimations of the temperature evolution process during essentially isothermal adsorption processes. It has been previously reported that during methane adsorption on coal, the temperature change induced by adsorption first shows a sharp increase to a peak, and then a gradual decrease to the environmental (bath) temperature at equilibrium [41]. Moreover, this change in temperature was not the same at different temperatures; at higher temperatures, a smaller temperature change occurred upon adsorption of methane on coal. Considering the fact that the physical adsorption of methane on either coal or shale should exhibit similar characteristics (both are bulk, naturally occurring carbonaceous organic-rich materials), these previous results are readily comparable to those obtained in this work. Herein it is found that the isosteric heat of adsorption decreases with increasing adsorption content for methane in shale, which is also affected by the temperature of the isotherms. Specifically, the isosteric heat of adsorption decreases as a function of temperature, which is qualitatively consistent with the observed temperature change upon methane adsorption on coal. The precise dependence of the isosteric heat of adsorption on both adsorption uptake and temperature must be taken into consideration for accurate modeling of the heat transfer process during methane extraction from shale.

The isosteric heat of adsorption of methane on shale in the Henry's law region is consistent with similar reports on coal samples [42]. In the Henry's law pressure range, each adsorbed molecule can explore the entire adsorbent surface independently because of the extremely low adsorbate concentration at low pressure. The adsorption sites of highest energy will be occupied first (in this work, "highest energy" refers to lowest (negative) absolute energy), and the interactions between adsorbed methane molecules and the gas molecules themselves can both be neglected. When the interaction among adsorbed methane molecules and/or gas molecules becomes significant with increasing pressure, the most accurate calculation of the isosteric heat of adsorption must consider both the real gas behavior and the finite adsorbed phase volume as in equation (13). Then, considering the interaction between the adsorbate molecules and the solid porous adsorbent as the only remaining significant interaction in the system, the evolution of the isosteric heat of adsorption as a function of pressure or adsorption uptake can reflect the overall heterogeneity of the adsorbent which is a very relevant property for comparison between materials [27, 42]. In addition, since the isosteric heat of adsorption in the Henry's law region is independent of temperature, as shown in equation (13), it can be used as a unique index to evaluate the adsorption affinity of the highest energy sites in porous adsorbents such as coal and shale. 


\section{Conclusions}

In this work, the isosteric heat of adsorption of methane on Longmaxi shale at geologically relevant pressures is obtained by considering both the real gas behavior of bulk methane and the finite adsorbed phase volume. The effects of real gas behavior, adsorbed phase volume, and temperature on the isosteric heat of adsorption are investigated, facilitated by the use of a two-site Langmuir adsorption model. Three conclusions can be drawn.

Firstly, for high pressure methane adsorption on shale, the isosteric heat of adsorption decreases with increasing adsorption uptake (or equilibrium pressure) and the dependence on temperature is negative.

Secondly, accurate calculations of the isosteric heat of adsorption are always lower than the quantity calculated using the $\mathrm{C}-\mathrm{C}$ approximation. Neglecting either the real gas behavior or the adsorbed phase volume always results in an overestimation of the isosteric heat. These results are consistent with the temperature evolution phenomenon that occurs during methane adsorption on other carbonaceous adsorbents.

Finally, the isosteric heat of adsorption in the Henry's law region, which is independent of temperature, can be used as a unique index to evaluate the gas adsorption affinity of adsorbents such as coal and shale in the limit of very dilute adsorption. For all thermodynamic analysis outside of this regime, a more sophisticated method such as fitting the data to a two-site Langmuir model must be employed.

\section{Acknowledgements}

Financial assistance for this work was provided by the U.S. Department of Energy through the National Energy Technology Laboratory's Program under Contract No. DE-FE0006827, the State Key Development Program for Basic Research of China (Grant No. 2014CB239102) and Department of Science and Technology at China Petroleum \& Chemical Corporation (Grant No.P12002, P14156). The first author also wants to thank Prof. Matthew R Hall for his valuable discussions on this work.

\section{Reference}

1. Kuuskraa, V., Stevens, S. H., \& Moodhe, K. D. (2013). Technically recoverable shale oil and shale gas resources: an assessment of 137 shale formations in 41 countries outside the United States. [J]. Natural Gas Industry, 5, 003.

2. Wang, Q., Chen, X., Jha, A. N., \& Rogers, H. (2014). Natural gas from shale formation-the evolution, evidences and challenges of shale gas revolution in United States. Renewable and Sustainable Energy Reviews, 30, 1-28.

3. Curtis, J. B. (2002). Fractured shale-gas systems. AAPG bulletin, 86(11), 1921-1938.

4. Montgomery, S.L., Jarvie, D.M., Bowker, K.A., Pollastro, R.M., 2005. Mississippian Barnett Shale, Fort Worth basin, north-central Texas: gas-shale play with multietrillion cubic foot potential. AAPG Bull. 89, 155e175.

5. Zhang, T., Ellis, G. S., Ruppel, S. C., Milliken, K., \& Yang, R. (2012). Effect of organic-matter type and thermal maturity on methane adsorption in shale-gas systems. Organic Geochemistry, 47, 120-131. 
6. Ross, D.J., Bustin, R.M., 2008. Characterizing the shale gas resource potential of DevonianeMississippian strata in the Western Canada sedimentary basin: application of an integrated formation evaluation. AAPG Bull. 92, 87e125.

7. Ross, D.J., Bustin, R.M., 2009. The importance of shale composition and pore structure upon gas storage potential of shale gas reservoirs. Mar. Pet. Geol. 26, 916e927.

8. Gasparik, M., Ghanizadeh, A., Bertier, P., Gensterblum, Y., Bouw, S., Krooss, B.M., 2012. Highpressure methane sorption isotherms of black shales from the Netherlands. Energy Fuels 26, $4995 \mathrm{e} 5004$.

9. Busch, A., \& Gensterblum, Y. (2011). CBM and CO2-ECBM related sorption processes in coal: a review. International Journal of Coal Geology, 87(2), 49-71.

10. Ji, W., Song, Y., Jiang, Z., Wang, X., Bai, Y., Xing, J., 2014. Geological controls and estimation algorithms of lacustrine shale gas adsorption capacity: a case study of the Triassic strata in the southeastern Ordos Basin, China. Int. J. Coal Geol. 134, 61e73.

11. Zou, Caineng, Dazhong, Dong, Yuman, Wang, Xinjing, Li, HUANG, J., Shufang, Wang, ... \& Wenhua, Bai. (2015). Shale gas in China: Characteristics, challenges and prospects (II). Petroleum Exploration and Development, 42(6), 753-767.

12. Saha, B. B., El-Sharkawy, I. I., Koyama, S., Lee, J. B., \& Kuwahara, K. (2006). Waste heat driven multi-bed adsorption chiller: heat exchangers overall thermal conductance on chiller performance. Heat Transfer Engineering, 27(5), 80-87.

13. Jee, J. G., Kim, M. B., \& Lee, C. H. (2005). Pressure swing adsorption processes to purify oxygen using a carbon molecular sieve. Chemical engineering science, 60(3), 869-882.

14. Schlapbach, L., \& Züttel, A. (2001). Hydrogen-storage materials for mobile applications. Nature, 414(6861), 353-358.

15. Biloe, S., Goetz, V., \& Mauran, S. (2001). Dynamic discharge and performance of a new adsorbent for natural gas storage. AIChE Journal, 47(12), 2819-2830.

16. Rahman, K. A., Chakraborty, A., Saha, B. B., \& Ng, K. C. (2012). On thermodynamics of methane+ carbonaceous materials adsorption. International Journal of Heat and Mass Transfer, 55(4), 565573.

17. Jaschik, M., Tanczyk, M., Warmuzinski, K., \& Wojdyla, A. (2015). Comments on the paper "On thermodynamics of methane+ carbonaceous materials adsorption". International Journal of Heat and Mass Transfer, 91, 1308.

18. Thommes M, Kaneko K, Neimark, A V, Olivier J P, Rodriguez-Reinoso F, Rouquerol J \& Sing K S. Physisorption of gases, with special reference to the evaluation of surface area and pore size distribution (IUPAC Technical Report). Pure and Applied Chemistry, 2015, 87(9-10):1051-1069.

19. Pan, H., Ritter, J. A., \& Balbuena, P. B. (1998). Examination of the approximations used in determining the isosteric heat of adsorption from the Clausius-Clapeyron equation. Langmuir, 14(21), 6323-6327.

20. Sircar, S., Mohr, R., Ristic, C., \& Rao, M. B. (1999). Isosteric heat of adsorption: theory and experiment. The Journal of Physical Chemistry B, 103(31), 6539-6546.

21. Shen, D., Bülow, M., Siperstein, F., Engelhard, M., \& Myers, A. L. (2000). Comparison of experimental techniques for measuring isosteric heat of adsorption. Adsorption, 6(4), 275-286.

22. Murialdo, M., Stadie, N. P., Ahn, C. C., \& Fultz, B. (2015). Observation and Investigation of Increasing Isosteric Heat of Adsorption of Ethane on Zeolite-Templated Carbon. The Journal of Physical Chemistry C, 119(2), 944-950.

23. Payne, S. H., Kreuzer, H. J., \& Roelofs, L. D. (1991). Isosteric heat of adsorption for repulsive interactions. Surface Science Letters, 259(3), L781-L786. 
24. Chung, D. S., \& Pfost, H. B. (1967). Adsorption and desorption of water vapor by cereal grains and their products Part I: Heat and free energy changes of adsorption and desorption. Transactions of the ASAE, 10(4), 549-0551.

25. Frost, H., Düren, T., \& Snurr, R. Q. (2006). Effects of surface area, free volume, and heat of adsorption on hydrogen uptake in metal-organic frameworks. The Journal of Physical Chemistry B, 110(19), 9565-9570.

26. Stadie, N. P., Murialdo, M., Ahn, C. C., \& Fultz, B. (2015). Unusual Entropy of Adsorbed Methane on Zeolite-Templated Carbon. The Journal of Physical Chemistry C, 119(47), 26409-26421.

27. Stadie, N. P., Murialdo, M., Ahn, C. C., \& Fultz, B. (2013). Anomalous isosteric enthalpy of adsorption of methane on zeolite-templated carbon. Journal of the American Chemical Society, 135(3), 990-993.

28. Dejardin, P. (1982). Determination of adsorption isotherms of macromolecules by the depletion method. The Journal of Physical Chemistry, 86(14), 2800-2801.

29. Bae, J. S., \& Bhatia, S. K. (2006). High-pressure adsorption of methane and carbon dioxide on coal. Energy \& Fuels, 20(6), 2599-2607.

30. Pini, R., Ottiger, S., Burlini, L., Storti, G., \& Mazzotti, M. (2010). Sorption of carbon dioxide, methane and nitrogen in dry coals at high pressure and moderate temperature. International Journal of Greenhouse Gas Control, 4(1), 90-101.

31. Sakurovs, R., Day, S., Weir, S., \& Duffy, G. (2007). Application of a modified DubininRadushkevich equation to adsorption of gases by coals under supercritical conditions. Energy \& fuels, 21(2), 992-997.

32. Myers, A. L., \& Monson, P. A. (2014). Physical adsorption of gases: the case for absolute adsorption as the basis for thermodynamic analysis. Adsorption, 20(4), 591-622.

33. Marmur, A. (2015). Surface tension and adsorption without a dividing surface. Langmuir, 31(46), 12653-12657.

34. Krishna, R. (2015). Evaluation of procedures for estimation of the isosteric heat of adsorption in microporous materials. Chemical Engineering Science,123, 191-196.

35. Askalany, A. A., \& Saha, B. B. (2015). Derivation of isosteric heat of adsorption for non-ideal gases. International Journal of Heat and Mass Transfer, 89, 186-192.

36. Tang, X., Ripepi, N., Stadie, N. P., Yu, L., \& Hall, M. R. (2016). A dual-site Langmuir equation for accurate estimation of high pressure deep shale gas resources. Fuel, 185, 10-17.

37. Rouquerol, J., Llewellyn, P., \& Rouquerol, F. (2007). Is the BET equation applicable to microporous adsorbents? Studies in surface science and catalysis, (160), 49-56.

38. Graham, D. (1953). The characterization of physical adsorption systems. I. The equilibrium function and standard free energy of adsorption. The Journal of Physical Chemistry, 57(7), 665669.

39. Mertens, F. O. (2009). Determination of absolute adsorption in highly ordered porous media. Surface Science, 603(10), 1979-1984.

40. Chakraborty, A., Saha, B. B., Koyama, S., \& Ng, K. C. (2006). On the thermodynamic modeling of the isosteric heat of adsorption and comparison with experiments. Applied physics letters, 89(17), 171901.

41. Yue, G., Wang, Z., Tang, X., Li, H., \& Xie, C. (2015). Physical Simulation of Temperature Influence on Methane Sorption and Kinetics in Coal (II): Temperature Evolvement during Methane Adsorption in Coal Measurement and Modeling. Energy \& Fuels, 29(10), 6355-6362. 
42. Tang, X., Wang, Z., Ripepi, N., Kang, B., \& Yue, G. (2015). Adsorption affinity of different types of coal: mean isosteric heat of adsorption. Energy \& Fuels, 29(6), 3609-3615.

515 